\title{
Wood fuel consumption, institutional quality, and forest degradation in sub-Saharan Africa: evidence from a dynamic panel framework
}

\begin{abstract}
The objective of this paper is to answer an empirical question regarding whether wood fuel consumption and institutional quality affect forest degradation in sub-Saharan Africa. To accomplish this, a sample of 45 sub-Saharan African countries covering 2005-2013 was employed. Also, the dynamic generalized method of moments (GMM) approach was used to estimate the specified model. The results indicated that wood fuel consumption significantly contributed to forest degradation in the region. On the other hand, control of corruption and government effectiveness were negatively related to forest degradation. This suggests that effective control of corruption and governance can contribute to lowering forest degradation in the region. Forest degradation aided by wood fuel consumption can be lessened by effective control of corruption and governance. Thus, policy makers should (1) provide adequate and affordable (or subsidized) modern fuels to the populace, especially rural dwellers, (2) intensify the fight against corruption, and (3) ensure effective governance.
\end{abstract}

Keyword: Wood fuel consumption; Institutional quality; Forest degradation; Control of corruption; Government effectiveness; System GMM 